\title{
Pemutaran Video, Diskusi dan Penggunaan Standing Banner pada Siswa untuk Mencegah Kecanduan Media Sosial
}

\author{
Laili Rahayuwati, Ryan Hara Permana, Mamat Lukman, Ahmad Yamin, Annisa Labertha \\ Fakultas Keperawatan Universitas Padjadjaran \\ Email: annisa.labertha@gmail.com
}

\begin{abstract}
Abstrak
Kecanduan media sosial adalah suatu masalah psikologis yang akan mengganggu produktifitas dan kemampuan belajar remaja. Kecanduan media sosial dipengaruhi oleh meningkatnya jumlah pengguna internet di media sosial. Beberapa kajian menunjukkan adanya masalah adiksi media sosial pada remaja di Indonesia. Tujuan dilakukannya pengabdian pada masyarakat ini adalah untuk memberikan kesadaran dan pemahaman remaja tentang bahaya adiksi media sosial internet. Materi yang disampaikan adalah: pengertian media sosial, dampak media sosial dan bagamana menanggulangi kecanduan pada media sosial. Pelaksanaan kegiatan metode yaitu: ceramah, video, powerpoint, diskusi atau tanya jawab yang terbuka untuk siswa, dengan penyampaian pesan melalui standing banner. Hasil menunjukkan bahwa sebagaian besar siswa menggunakan internet. Berdasar evaluasi proses peserta terlihat antusias saat pemberian materi berlangsung. Peserta mengikuti dengan senang hati karena penyuluhan dilaksanakan dengan menyenangkan. Kegiatan berjalan kondusif dan diskusi berjalan sangat aktif. Respon siswa baik, dapat dilihat dari saat mulai kegiatan penambahan peserta pun cukup banyak. Didukung oleh keterlibatan guru sejak awal sampai akhir sangat baik. Simpulan adalah diperlukan suatu program yang kontinyu dalam kegiatan yang berlangsung selanjutnya yang menyasar remaja di sekolah sekolah. Dukungan

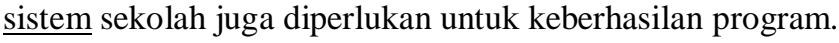

Kata kunci: Kecanduan, media social, standing banner.

\begin{abstract}
Social media addiction is a psychological problem impacting the productivity and adolescents' capability. Social media addiction was triggered by the rise of internet social media users. Some studies show that in adolescents in Indonesia face problems of media social addiction. The purpose of community service is to provide adolescent awareness and understanding of the impact of internet social media addiction. The health education materials presented were: the impact of the media and how to deal with addiction to social media. The method activities were: lectures, videos, powerpoints, discussions or question and answer, and delivering messages for months through standing banner. The results show that almost all teens use the internet. Based on process evaluation the participants were enthusiastic. Participants looked very happily because health education was carried out pleasantly. Activities run conducive and discussions run very actively. The response of student were good after health education. By qualitative evaluation, there are increasing awareness and knowledge of student. The involvement of teachers from the beginning to the end is very good. Conclusion: there are needed the regular and continuing program in the following activities which targeting youth in school. School system support is also needed for the success of the program.
\end{abstract}

Keywords: Addiction, social media, standing banner. 


\section{Pendahuluan}

Kecanduan media sosial pada remaja akan menimbulkan dampak yang buruk. Salah satunya adalah fenomena munculnya rasa ketakutan akan kehilangan momen berharga karena individu tersebut tidak dapat hadir didalamnya dan selalu ingin terhubung dengan apa yang dilakukan orang lain di media sosial (Przybylski et al., 2013). Kejadian tersebut disebut juga Fear of Missing Out, merupakan gangguan kesehatan psikologis yang dapat mengindikasikan timbulnya kecemasan apabila tidak membuka media sosial (Thompson, 2012).

Hasil survei Kominfo (2017) terdapat sebanyak 88 juta pengguna pada tahun 2015. Pada tahun 2016 di Indonesia mengalami peningkatan yang signifikan sebanyak 51,8\% dari tahun sebelumnya yaitu menjadi 132,7 juta pengguna, dan pada tahun 2017 mengalami peningkatan 11 juta yaitu menjadi 143 juta pengguna dan paling banyak yang diakses dari internet ialah media sosial yaitu sebesar $87,13 \%$. Penggunaan internet terbanyak ialah di Pulau Jawa dengan persentase mencapai 58,08\% yaitu sebesar 20,7 juta pengguna. Survei ini juga mengkomposisikan penggunaan internet berdasarkan usia, angka terbesar berada pada usia 13-18 tahun, yakni sebesar 75,50\%. Menurut penelitian (Gezgin, Hamutoglu, Gemikonakli, \& Raman, 2017) menemukan bahwa usia dibawah 21 tahun memungkinkan mengalami Social Media Addiction.

Usia remaja pertengahan (15-18 tahun) sudah mulai ingin menentukan apapun menurut dirinya sendiri, serta tidak ingin banyak dicampuri oleh perlakuan orang tua (Monks, 2009). Selain itu pada usia remaja pertengahan juga lebih sering melakukan pencarian hal baru seperti selalu berusaha untuk mendapatkan informasi yang mereka inginkan salah satunya dengan menggunakan internet termasuk menggunakan media sosial, karena usia remaja pertengahan ingin lebih merasakan kebebasan karena pada masa awal remaja mereka tertunda akan kebebasannya (Pickhardt, 2009). Maka lebih memungkinkan adanya kebebasan dalam penggunan ponsel pada remaja pertengahan daripada remaja awal yang dilihat dari sikap yang mereka munculkan terhadap orang tua. Dalam hal tersebut maka kami lebih memilih melakukan pendidikan kesehatan kepada usia remaja pertengahan yaitu pada siswa SMA. 
Salah satu kecanduan internet yang berkaitan dengan media sosial seperti instagram ialah Cyber-relationship addiction, yaitu individu akan mengalami kecanduan dalam hal berteman di dunia maya (Young, 2011). Media sosial seperti instagram jika dimainkan secara terus menerus maka akan menjadikan individu tersebut tidak ingin lepas dari ponselnya. Hal ini dapat berdampak negatif pada siswa remaja apabila dibiarkan karena dapat menimbulkan faktor resiko seperti prestasi belajar yang menurun karena terlalu lama memainkan ponselnya. Didukung juga oleh penelitian (Wati \& Sodik, 2018) didapatkan dari hasil penelitiannya bahwa dampak negatif dari kecanduan media sosial dimana menjadikan intensitas pemakaian ponsel meningkat sehingga remaja sekolah menjadi malas untuk belajar.

Hasil studi pendahuluan dilakukan pada tanggal 14 November 2018 di SMAN Jatinangor, terlihat tidak sedikit siswa yang menggunakan ponselnya ketika di kelas, di kantin, serta ketika siswa jalan di koridor sekolah. Selain itu telah dilakukan juga wawancara terhadap 6 siswa di kelas XI MIPA 2, terdiri dari 3 siswa laki laki dan 3 siswa perempuan pada tanggal 14 November 2018 di SMAN Jatinangor. 3 siswa tersebut dinyatakan berprestasi tinggi di kelasnya dan 3 siswa lagi dinyatakan berprestasi rendah, pernyataan tersebut didapatkan dari wali kelas XI MIPA 2. Semua siswa yang diwawancara mengakui bahwa memiliki akun media sosial yang sering diakses yaitu instagram. Berdasarkan hasil wawancara yang penulis dapatkan, menunjukkan bahwa intensitas penggunaan ponsel rata-rata pada siswa yang berprestasi rendah ialah 2-3 jam dalam sekali memegang ponsel, dan rata-rata intensitas penggunaan ponsel pada siswa yang berprestasi tinggi sekitar 15-30 menit dan hanya waktu tertentu saja mereka menggunakan ponsel dengan intensitas yang lama itupun dalam konteks mereka browsing tentang pelajaran. Penggunaan ponsel adalah untuk interaksi media sosial, game, dan browsing informasi popular. Dapat disimpulkan bahwa penggunaan ponsel ini memang sangat mempengaruhi prestasi belajar pada siswa. Prestasi siswa diukur dari informasi yang didapat di sekolah. Prestasi tinggi adalah 1-10 dengan nilai terbaik, prestasi sedang 30-11 urutan nilai/ranking, dan prestasi rendah adalah 31-50 urutan nilai. Kejadian adiksi media sosial, berdasar informasi guru sekolah, terjadi pada siswa di SMA Negeri Jatinangor, namun 
masih banyak siswa yang belum mengetahui hal tentang adiksi media sosial. Kejadian ini sebaiknya ditangani agar tidak mengganggu prestasi belajar pada siswa, karena fenomena adiksi media sosial ini sebenarnya dapat terjadi pada siapa saja yang telah menggunakan media sosial yang terakses dari internet.

Peran perawat dalam ranah komunitas ialah sebagai edukator dan konselor dapat memberikan konseling atau arahan untuk anak usia remaja sekolah khususnya di lingkungan sekolah untuk meningkatkan kesejahteraan psikologis pada remaja di sekolah. Selain itu perawat dapat memberikan dorongan kepada guru dan orang tua untuk melakukan pendampingan kepada remaja dalam membatasi penggunaan ponsel khususnya media sosial agar lebih bijak dalam penggunaan ponsel. Berdasarkan hal tersebut maka sangat penting dilakukan pendidikan kesehatan tentang bahaya kecanduan media sosial pada siswa.

\section{Metode}

Program pengabdian masyarakat dilaksanakan di SMA Negeri Jatinangor, Kabupaten Sumedang, Jawa Barat. Sasaran dari program ini adalah anak usia sekolah menengah atas, karena siswa remaja pada usia tersebut mayoritas sudah mengakses media sosial pada ponselnya dan sering digunakan maupun di rumah atau di sekolah.

Metode pelaksanaan pada program penyuluhan masyarakat ini dilaksanakan secara sistematis. Berikut gambaran flow map: 1) Pemilihan daerah sasaran; 2) Survei daerah sasaran; 3) Observasi lapangan; 4) Penyusunan materi penyuluhan; 5) Rencana penyuluhan; 6) Izin pelaksanaan; 7) Sosialisasi program; 8) Pelaksanaan program; 9) Laporan akhir.

1. Pemilihan daerah sasaran yang akan digunakan untuk sosialisasi

Tim berdiskusi untuk sasaran yang tepat dilihat dari fenomena yang ada dan mencari informasi tentang penelitian maupun pendidikan kesehatan yang sudah pernah diberikan di berbagai SMA

2. Survei daerah sasaran 
Tim berdiskusi dengan yang sudah pernah melakukan penelitian di SMA Negeri Jatinangor dan menanyakan tentang kondisi siswa ketika didatangi oleh mahasiswa. Hasil informasi yang didapat menetapkan SMA Negeri Jatinangor sebagai daerah sasaran.

3. Melakukan pengamatan terhadap sekolah menengah atas yang ditetapkan Tim menanyakan sikap siswa kepada yang pernah melakukan penelitian serta fenomena yang berkaitan dengan kecanduan media sosial. Hasil informasi juga sudah menggambarkan bahwa fenomena kecanduan media sosial memang ada di sekolah tersebut.

Hasil pengkajian kebutuhan belajar didapatkan bahwa kebutuhan belajar siswa SMA Negeri Jatinagor, meliputi kebutuhan belajar perceived needs, unperceived needs, dan misperceived needs.

4. Penyusunan materi untuk Pendidikan kesehatan

Materi didiskusikan dalam tim

5. Menyusun jadwal Pendidikan kesehatan

Tim mendiskusikan waktu, kemudian tim humas mendatangi ke sekolah untuk memberitahukan tujuan dan maksud serta menentukan tanggal yang cocok untuk jadwal pemberian Pendidikan kesehatan.

6. Izin pelaksanaan untuk pendidikan kesehatan

Tim humas membuat surat izin Fakultas Keperawatan, kemudian tim humas memberikan surat tersebut kebagian humas sekolah untuk persetujuan.

7. Sosialisasi program kepada sasaran

Tim mendatangi ke sekolah untuk menjelaskan rencana Pendidikan kesehata di sekolah.

8. Pelaksanaan program penyuluhan

Setelah semua persiapan telah selesai, tim berkumpul dari pagi dan menyiapkan 2 kelas yang akan di pakai di sekolah.

Materi Pendidikan kesehatan meliputi: 1) Dampak positif media sosial; 2) Dampak negatif media sosial; 3) Penyebab kecanduan media sosial; 4) Cara mengatasi kecanduan media. Penerapan materi tersebut bersifat sharing untuk siswa melalui: ceramah serta menampilkan video, diskusi 
Laili Rahayuwati: Pemutaran Video, Diskusi dan Penggunaan Standing Banner

atau tanya jawab yang terbuka untuk siswa. Selain itu dilakukan pemasangan Standing Banner yang berisi tentang materi Pendidikan kesehatan.

\section{Laporan akhir}

\section{Hasil}

Pembelajaran tentang kecanduan media sosial sangat diperlukan, di mana sekolah ini sudah dilakukan penelitian bahwa di sekolah tersebut mengalami kecanduan media sosial yang tinggi. Idealnya ketika kita sudah mengetahui apa saja yang terjadi pada diri kita sehingga merugikan kehidupan, sudah pasti kita dapat menghindari hal-hal tersebut yang dapat merugikan kita. Dalam program ini akan ditekankan kepada siswa agar menghindari dari sikap yang dapat menjadikan siswa kecanduan terhadap media sosial.

Di SMA Negeri Jatinangor ini juga terfasilitasi Wi-Fi dimana siswa dapat kapan saja menggunakannya. Hal tersebut bertujuan untuk mempermudah siswa dalam proses belajarnya. Namun, dari hal tersebut masih banyak siswa yang menggunakannya untuk kebutuhan lain seperti mengakses media sosial pada ponselnya. siswa pun tidak menyadari bahwa dengan terlalu sering mengakses media sosial itu dapat menyebabkan kecanduan pada dirinya sehingga muncul dampak negatif yang dapat merugikan dirinya serta mengganggu proses belajar. Maka, pemberian informasi mengenai bahaya kecanduan media sosial menjadi sorotan penting.

Berdasarkan hasil rekapitulasi hasil pengkajian kebutuhan belajar dapat terlihat bahwa pada sebagian siswa SMA Negeri Jatinangor, kebutuhan belajar yang termasuk kedalam kebutuhan belajar: 1) Perceived needs. Karena ada sebagian mengetahui dampak dari kecanduan media sosial yang berbahaya bagi kesehatan; 2) Unperceived needs. Karena ada sebagian siswa yang belum mengetahui dampak dari kecanduan media sosial yang berbahaya bagi kesehatan; 3) Misperceived needs. Karena ada sebagian siswa yang mengetahui jika bahaya kecanduan media sosial berbahaya, tetapi masih tetap menggunakannya secara 
berlebihan. Selanjutnya, berdasar data rekapitulasi hasil pengkajian kebutuhan belajar, maka ditentukan: 1) Jumlah audience: 70 orang; 2) Audience berusia: 1516 tahun.

Kegiatan pendidikan kesehatan yang dilaksanakan pada periode MaretApril 2019 di SMA Negeri Jatinangor mulai dari persiapan sampai evaluasi. Pelaksanaan pendidikan kesehatan 15 April 2019. Tim melakukan pemasangan banner saat kegiatan pendidikan kesehatan berlangsung, ditujukan agar siswa terpapar dengan informasi kecanduan media sosial, serta agar siswa selalu mengingat apa yang sudah diberikan oleh tim sehingga akan bermanfaat untuk jangka panjang.

Jumlah audience menjadi \pm 70 orang dibagi menjadi 2 kelas A dan B kelas XI saja. Setiap siswa mengisi daftar hadir yang disertai email siswa untuk mengirimkan e-sertifikat sebagai tanda bukti siswa sudah berpartisipasi dalam kegiatan ini. Kegiatan ini dimulai dengan pembukaan dan menanyakan sejauh mana siswa mengetahui tentang kecanduan media sosial, apakah siswa pernah mengalaminya, dan dampak apa saja yang muncul apabila mengalami kecanduan media sosial. Dari semua jawaban siswa, siswa cukup mengenal dengan kecanduan media sosial, namun siswa masih belum paham mengenai dampak apa saja yang akan timbul pada siswa yang mengalami media sosial serta cara menanganinya.

Kegiatan dilanjutkan dengan pemberian materi menggunakan PPT (powerpoint) dan penampilan video. Materi yang disampaikan ialah mengenai bahaya kecanduan media sosial. Setelah video selesai ditampilkan, pemateri langsung menampilkan PPT yang sudah disiapkan. Saat sesi pematerian berjalan dengan lancar dan peserta tampak fokus dan memperhatikan apa yang sedang dipresentasikan.

Setelah penyajian materi melalui PPT, dilanjutkan ceramah singkat, hal tersebut bermaksud sharing kepada siswa agar tidak terlalu terlihat menggurui maka pemateri pun sambil berinteraksi dengan siswa. Setelah materi selesai disampaikan, dilanjut dengan sesi tanya jawab yang bertujuan untuk mengetahui sejauh mana perubahan siswa dari yang sebelumnya dan sesudahnya diberikan 
penkes. Tim menyediakan doorprize untuk yang dapat menjawab pertanyaan, dan bertujuan sebagai apresiasi siswa yang mempunyai motivasi dan perhatian terhadap kegiatan. Pertanyaan dibacakan oleh pemateri dan peserta antusias untuk menjawab pertanyaan, total ada 5 pertanyaan yang dijawab semua dengan benar oleh 5 orang peserta.

Berdasar observasi dab evaluasi saat sesi penutup, 16 siswa menyatakan puas dengan apa yang disampaikan. Beberapa siswa yang menanyakan tentang materi, terlihat baru mengetahui informasi lebih dalam lagi tentang kecanduan media sosial. Setelah sesi tanya jawab siswa juga telah ingin mengurangi penggunaan media sosial dan akan memanfaatkan waktu lebih baik lagi. Setelah doa penutupan dan foto bersama, maka dua buah (2) banner yang terpasang dijadikan tanda terimakasih sekaligus untuk reminder setiap saat kepada siswa karena ada pesan pesan di dalamnya.

\section{Pembahasan}

Berdasar evaluasi proses, peserta terlihat antusias saat pemberian materi berlangsung. Peserta mengikuti dengan senang hati karena penyuluhan dilaksanakan dengan menyenangkan. Kegiatan berjalan kondusif karena siswa memperhatikan materi yang disampaikan dengan baik. Hal ini dibuktikan dengan banyaknya siswa yang tertarik untuk menjawab pertanyaan ketika sesi tanya jawab. Meskipun dari sisi teknis pemberian media dan video harus didampingi dengan penjelasan. Respon siswa dan guru yang baik, dapat dilihat dari saat mulai kegiatan penambahan peserta pun cukup banyak. Guru di sekolah juga bertanggapan baik kepada tim dari awal hingga akhir kegiatan.

Keterbatasan kegiatan ini adalah, proses evaluasi tidak dilakukan secara kuantitatif, namun lebih ke arah kualitatif. Harapan ke depan adalah kombinasi dari evaluasi akan berpengaruh terhadap keberhasilan monitoring program.

Ditinjau dari proses terjadinya perubahan perilaku dalam Health Belief Model, perilaku akan berubah salah satunya yaitu jika individu diberikan pemahaman tentang keuntungannya. Dicari dulu penyebab dari suatu perilaku 
yang kurang baik, lalu diberikan penyuluhan serta informasi yang terinci tentang keuntungan dari perbaikan perilakunya. Upaya ini dilakukan dalam pendidikan kesehatan di SMA Negeri Jatinangor (McKenzie, J., Neiger, B., Thackeray, R. (2009).

Dalam transtheoritical model perubahan perilaku dimaknai sebagai proses perkembangan yang berlangsung dalam rentang waktu tertentu dan melalui beberapa tahap. Dalam proses pendidikan kesehatan ini, pengajar dapat mengetahui peserta didiknya berada pada tahap apa. Selama proses pendidikan kesehatan diketahui bahwa mayoritas peserta didik berada pada tahap contemplation yaitu individu berada dalam tahap lebih peduli terhadap sisi positif dan negatif dari perubahan perilaku yang direncanakan, namun masih merasa bimbang untuk benar-benar akan melakukannya, sehingga hal ini dapat menjadikan individu menunda perubahan (Dewi, et.al, 2018).

Theory of Reasoned Action akan berhasil ketika diaplikasikan pada perilaku yang di bawah kendali individu yang bersangkutan. Jika perilaku tersebut tidak sepenuhnya di bawah kendali atau kemauan individu, ia mungkin tidak akan secara nyata menampilkan perilaku tersebut, dalam hal ini yaitu membatasi penggunaan media sosial. Selama proses pendidikan kesehatan, pengajar berusaha agar individu mempunyai motivasi dan secara mandiri dapat berubah (WHO, 1998).

\section{Simpulan}

Proses pelaksanaan penyuluhan; siswa SMA Jatinangor, terlihat antusias saat pemberian materi berlangsung. Peserta mengikuti penyuluhan dengan senang hati karena kegiatan dilaksanakan dengan menyenangkan. Kegiatan penyuluhan berjalan kondusif karena siswa memperhatikan materi yang disampaikan dengan baik. Namun, evaluasi teknis adalah penggunaan media pembelajaran yang tidak terlihat sampai bangku siswa ke belakang.

Penyuluhan ke depannya diusahakan menggunakan proyektor yang diletakkan di depan dan di tengah supaya dapat terlihat jelas hingga belakang, 
jumlah fasilitator disesuaikan yaitu 7 orang dengan banyaknya audience yaitu 70 siswa.

\section{Ucapan Terimakasih}

Kegiatan Pengabdian Pada Masyarakat ini dapat terselenggara karena kerja keras tim mahasiswa Fakultas Keperawatan. Ucapan terimakasih disampaikan kepada: Karunia Adiyuda Dilaga, Nanda Hariyawinata, Yuli Anggia, Rivada Natasya Fadillah, Nada Shofi Salsabila, Faiza Zulfikar Sa'ban, Naufal Hafizh Fauzan, Shelen Indah Tripriantini Nenden Budiani Hanum, Rery Yuliani Pratiwi.

\section{Daftar Pustaka}

Addin Mendeley Bibliography Csl_Bibliography Firdaus, A. (2018). Hubungan antara fear of missing out (fomo) dengan kecanduan media sosial pada remaja skripsi. Universitas Islam Negeri Sunan Ampel Surabaya.

Chandra, M., Kohn, C., Pawlitz, J., Powel, G. (2016). Real cost of styrofoam. St. Louis University.

Elhai, J. D. (2016). Fear of missing out, need for touch, anxiety and depression are related to problematic smartphone use, 63, 509-516.

Dewi, R., Janitra, P. A., \& Aristi, N. (2018). Pemanfaatan Internet Sebagai Sumber Informasi Kesehatan Bagi Masyarakat. Media Karya Kesehatan, $1(2)$.

Gezgin, D. M., Hamutoglu, N. B., Gemikonakli, O., \& Raman, İ. (2017). Social Networks.

Users: Fear of Missing Out in Preservice Teachers. Journal of Education and Practice, (July), 13.

Herman, D. (2011). Do You Have FOMO: Fear Of Missing Out? Retrieved from http://www.danherman.com/The-Fear-of-Missing-Out-(FOMO)-byDanHerman.html.

Kimberly S. Young (Ed.). (2011). Internet Addiction: a Handbook and Guide to Evaluation and treatment. John Wiley. 
Kominfo. (2017). Perilaku Pengguna Internet Indonesia. Retrieved from https://web.kominfo.go.id/sites/default/files/Laporan Survei APJII_2017_v1.3.pdf.

McKenzie, J., Neiger, B., Thackeray, R. (2009). Health Education and Health Promotion. Planning, Implementing, \& Evaluating Health Promotion Programs. (pp. 3-4). 5th edition. San Francisco, CA: Pearson Education, Inc.

Monks. (2009). Tahap Perkembangan Masa Remaja. Medical Journal New Jersey Muagman. Jakarta: Grafindo.

Pickhardt, C. E. (2009). Rebel with a Cause: Rebellion in Adolescence. Psychology Today.

Przybylski, A. K., Murayama, K., Dehaan, C. R., \& Gladwell, V. (2013). Motivational, emotional, and behavioral correlates of fear of missing out. Computers in Human Behavior, 29(4), 1841-1848. https://doi.org/10.1016/j.chb.2013.02.014.

Thompson, J. W. (2012). JWT: Fear of Missing Out (FoMO). In Fear Of Missing Out (FOMO).

Wati, N. R., \& Sodik, M. A. (2018). Dampak Kecanduan Gadget di Kalangan Anak Sekolah, 2-10.

Wilda, F. S. (2018). Hubungan Antara Fear Of Missing Out Dengan Kecanduan Internet Kepada Mahasiswa.

World Health Organization. (1998). List of Basic Terms. Health Promotion Glossary. (pp. 4). Retrieved May 1, 2009

from http://www.who.int/hpr/NPH/docs/hp_glossary_en.pdf. 